\title{
NEW HIPS FOR OLD
}

\author{
By Kenneth H. Pridie, F.R.C.S.
}

Hon. Orthopaedic Surgeon, Bristol Royal Hospital; Lecturer in Orthopaedics, University of Bristol

This amazing advance in surgery is due to the work of Smith Petersen of America. The brilliance of his cup arthroplasty lies in an entirely new principle.

Any operation for replacement of the femoral head and neck by a metal or plastic substitute would tend to have the potential weakness that wear and strain might cause loosening at the bone-metal junction.

In the cup arthroplasty operation the metal cup on the head of the femur is fully floating and loose both in the acetabulum and on the head of the femur. Any looseness which may occur from wear and tear of usage will, within limits only, improve the function of the arthroplasty.

\section{Indication}

This operation is of special value for cases of bilateral osteo-arthritis with adduction and flexion. It can be performed at any age, the younger the patient is, provided the skeleton has reached its full size, the better. If the muscles are in a good condition, and only the bones are locked, the results will be excellent ; so good, in fact, that after the operation the patients will walk normally.

If the patients are very elderly, 60-70, and arthritis has been present for a very long time, then the muscles will be fibrosed and nonelastic and this will limit the functional result.

Destruction of the head by large cystic spaces may destroy the head so much that an undue amount of bone will have to be removed to get a good cup-bearing surface.

Removal of bone from the neck reduces the gluteal leverage and even quite a small loss of bone will so effect the mechanical leverage of the glutei that the patient will always walk with a limp, the gluteal limp very like that of a congenital hip luxation. If, therefore, for any reason I have to remove an excess of bone from the head or deepen the acetabulum (which comes to the same thing) I always displace the greater trochanter outwards when refixing this structure to the femur.

Adduction deformity without pain can be simply treated by an osteotomy which is the most universally useful operation on the hip. It needs no great surgical skill for a successful result. It is, although an easy operation to perform, quite difficult to maintain the position of correction. Even in plaster of paris the position may slip and become an osteotomy without correction. Therefore I always use traction as after-treatment for osteotomy of the femur. The traction method gets away from the two main disadvantages of the plaster method, first, the tendency to adduct and, secondly, stiffness of the knee after prolonged fixation in plaster, particularly in old people.

Arthrodesis is most useful in the young adult who wants to join the rough and tumble of life and to have a limb which will wear a life-time without trouble. In a successful arthrodesis the stiff hip will not give trouble. It is the lower lumbar spine and the opposite hip that have to do an extra share of work.

The arthroplasties aim at movement. The greatest degree of movement is obtained in removal of the head and neck of the femur as advocated by Mr. Girdlestone. This operation is especially indicated in those cases of spondylitis ankylopoietica where the hips and spine are affected. In cases of osteo-arthritis, however, the instability after this operation is a disadvantage. 


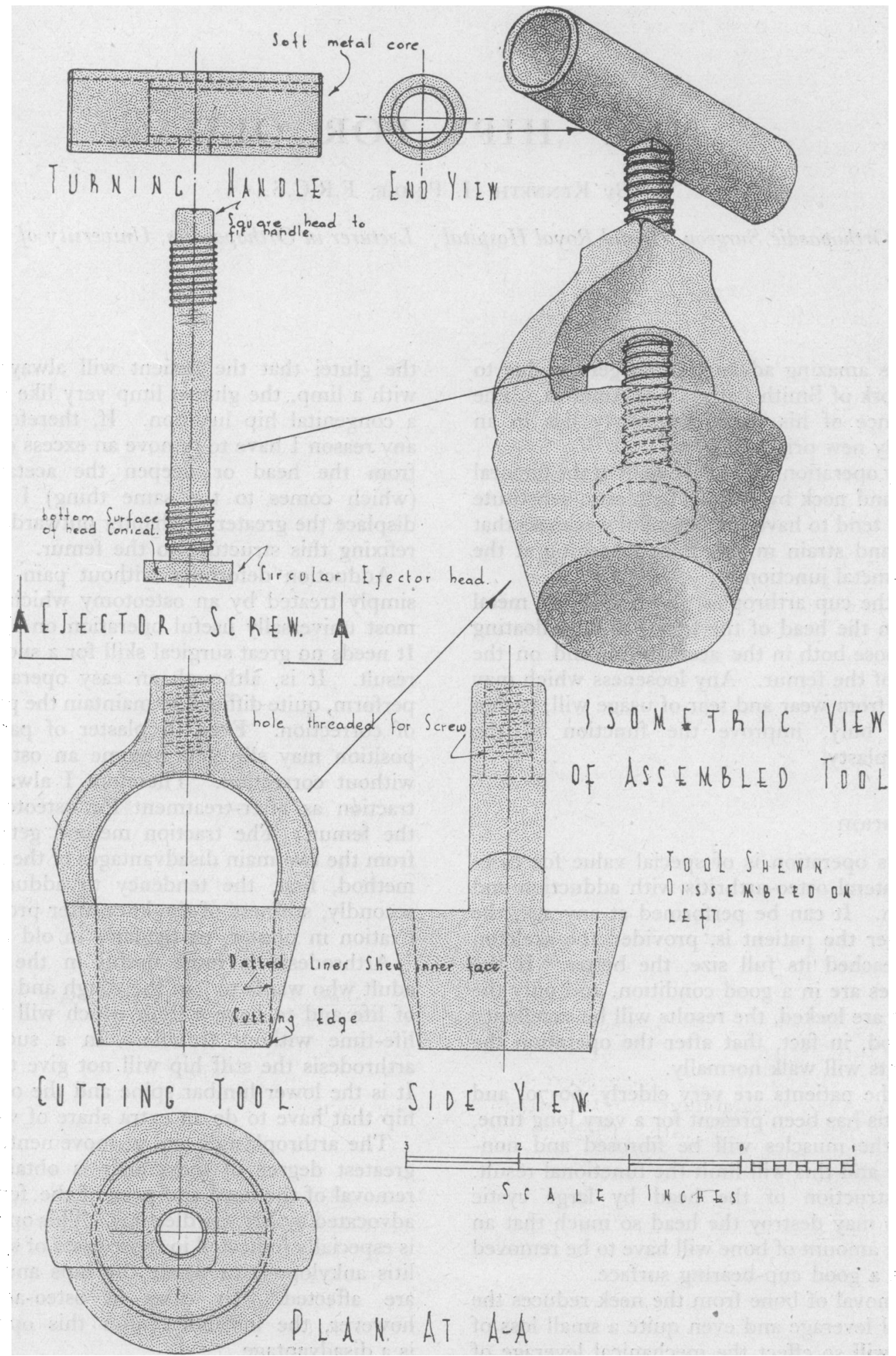

The Author's s'lf-extracting pun:h for cutting the femoral head. 
The cup arthroplasty for cases of unilateral or bilateral arthritis is a far more finished and efficient operation and the results more closely resemble the function of a normal hip. This operation has the following advantages:

I. There is little shock and even patients of over 70 can stand the operation without being transfused.

2. The patients start walking at five weeks and some walk exceedingly well without a stick at eight weeks from the day of operation.

3. The avoidance of plaster or prolonged immobilization prevents stiffness of the knee.

4. The patients can sit, walk and stand almost normally.

The operation has been improved and modified since its introduction by Smith Petersen. The main objections to his method are :

1. The anterior approach to the hip joint is a poor one which does not drain well and is liable to develop haematomata and infections.

2. The division of rectus femoris is an insult which the locomotor system never forgives.

3. The exposure of the acetabulum by stripping sub-periostially both aspects of the ilium sets free too many bone cells which form bone in the gluteal muscles and may lock the abductors of the hip.

4. With this anterior incision the approach to the acetabulum is poor, unless a large piece of the head of the femur is removed. The gluteal leverage is lost after much removal of bone.

The lateral approach which I have developed for this operation gets over these disadvantages and for it I claim that the drainage is excellent. The view of the acetabulum is good and the ilium is not interfered with. Consequently there is less bone formation about the hip joint after the operation. If the head of the femur has to be shortened the gluteal leverage can be increased by transplanting the greater trochanter outwards.

The description of the operation is as follows :

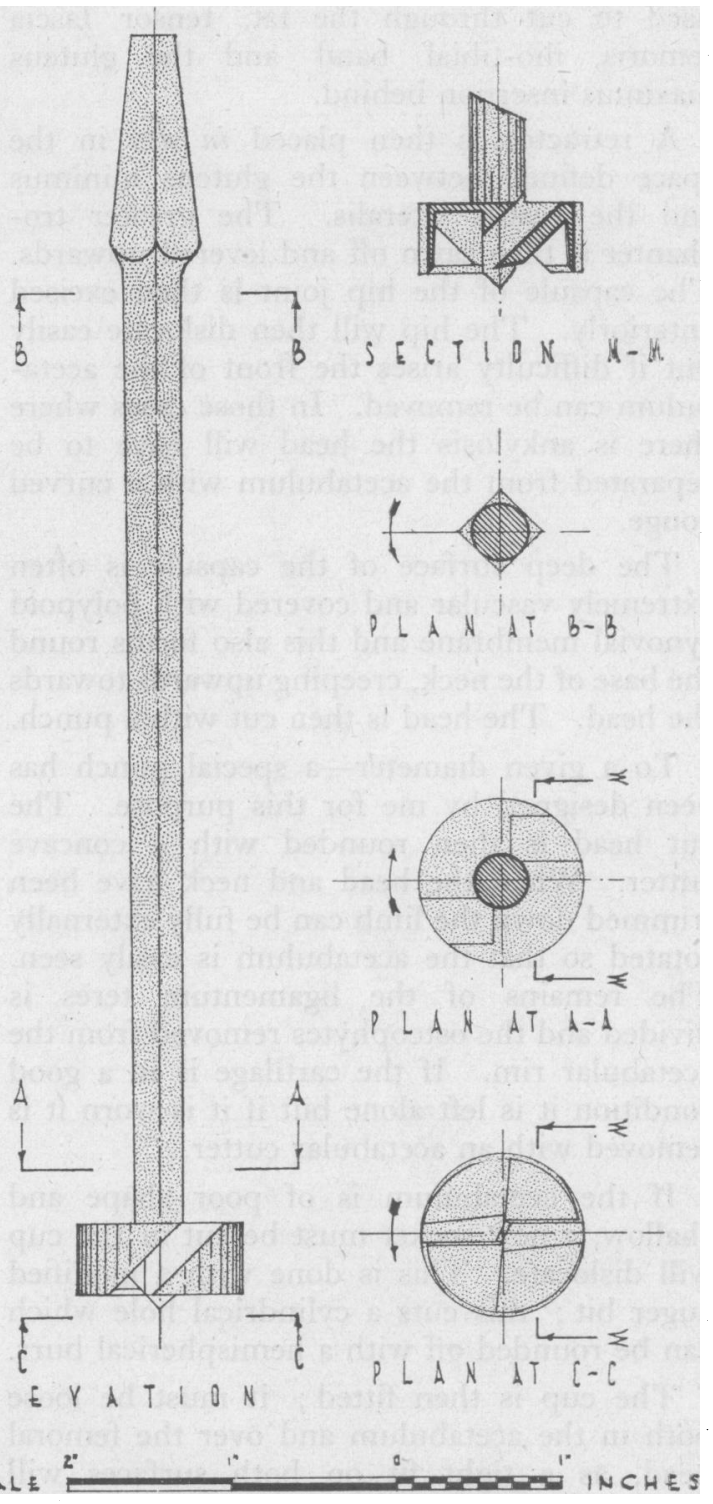

The Author's acetabular cutter.

The incision

From just lateral and above the anterior superior iliac spine downwards and outwards in the line of the neck of the femur, round the femur below the greater trochanter at about the level of the insertion of a Smith Petersen fracture pin, to the posterior aspect of the thigh. The skin incision having been made with a scalpel, a diathermy cutting needle is 
used to cut through the fat, tensor fascia femoris, ilio-tibial band and the gluteus maximus insertion behind.

A retractor is then placed in situ in the space defined between the gluteus minimus and the vastus lateralis. The greater trochanter is then sawn off and levered upwards. The capsule of the hip joint is then excised anteriorly. The hip will then dislocate easily but if difficulty arises the front of the acetabulum can be removed. In those cases where there is ankylosis the head will have to be separated from the acetabulum with a curved gouge.

The deep surface of the capsule is often extremely vascular and covered with polypoid synovial membrane and this also forms round the base of the neck, creeping upwards towards the head. The head is then cut with a punch.

To a given diameter-a special punch has been designed by me for this purpose. The cut head is then rounded with a concave cutter. When the head and neck have been trimmed down the limb can be fully externally rotated so that the acetabulum is easily seen. The remains of the ligamentum teres is divided and the osteophytes removed from the acetabular rim. If the cartilage is in a good condition it is left alone but if it is worn it is removed with an acetabular cutter.

If the acetabulum is of poor shape and shallow, a new socket must be cut or the cup will dislocate. This is done with a modified auger bit; this cuts a cylindrical hole which can be rounded off with a hemispherical burr.

The cup is then fitted; it must be loose both in the acetabulum and over the femoral head, as a tight fit on both surfaces will prevent movement, while a loose fit gives free movement.

The incision is then closed and the greater trochanter being fixed back in position by a $2 \frac{1}{2}$-in. wood screw which must engage the inner cortex of the femur otherwise the greater trochanter will be avulsed from the femur when the patient starts to walk.

The patient is put back in bed on Russell traction using a Pridie beam, and a 5-lb. weight is applied, with the bed tilted $\mathrm{I} \mathrm{ft}$. and the leg being kept in a position of abduction, slight flexion and internal rotation.
Movements are started at the end of the first week, weight bearing on the fifth week, and traction is oniy used at night after the fifth week. Patients on an average leave hospital on the seventh week.

\section{Results}

During the last six years I have performed the operation on 70 patients.

In the first four-year period I2 I operations were performed for arthritis of the hip and the analysis of these cases shows that the commonest operation has been osteotomy.

Osteotomy : 45 cases.

Cup arthroplasty : 20 cases, using the new Smith Petersen approach as used by Dr. Wallace Cole.

Twenty-eight operations: I2 unilateral, 8 bilateral.

Excision of the head and neck (Girdlestone) : 14 cases.

Arthrodesis : 22 cases ; Watson Jones' method, 12 cases; other methods, ro cases.

\section{Other types of operation}

As this was a new method of treatment this operation was first used on only very severe cases. Patients who were so bad that they were almost bedridden and could not earn their own living. If the operation was not successful it would not have meant economic ruin to them as their earning capacity had gone anyway and they were all patients over 50. They were in great pain and it was felt that the operation could hardly have made them any worse.

The factors I wished to determine were:

1. Is the patient relieved of pain ?

2. Is useful movement obtained ?

3. How long will this type of arthroplasty last ?

4. On what type of case should this operation be performed?

5. What are the contra-indications ?

6. What are the complications ?

In my review of these cases last year, five years after the first operation I appear to have found certain interesting facts : 


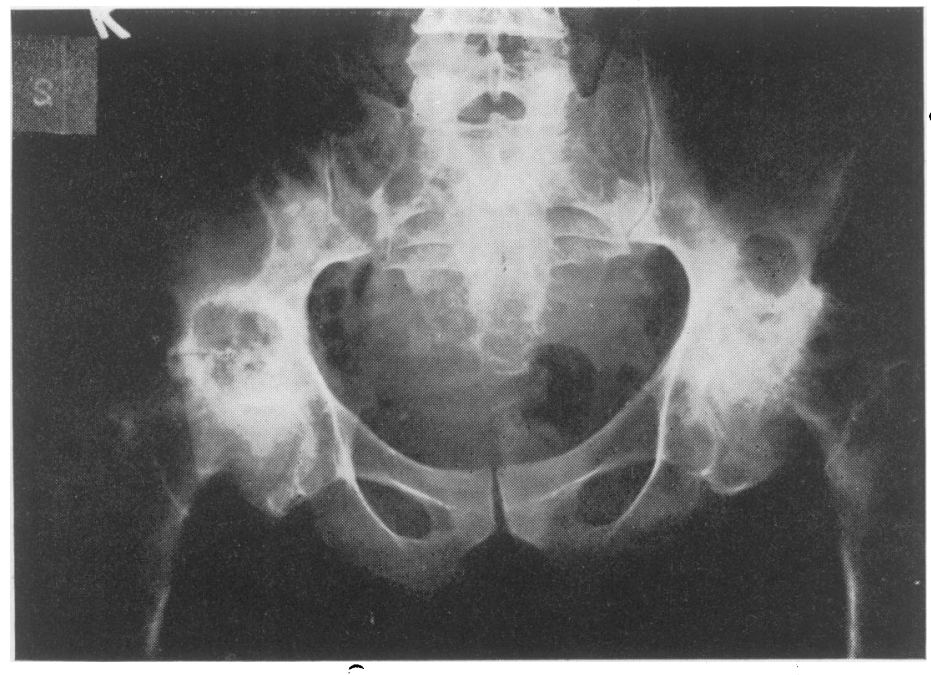

Severe bilateral osteo-arthritis secondary to cystic changes in the head of the femur and in the acetabuli.

Case One. As shown in picture 2. Shallow hip with secondary aseptic necrosis of head and secondary arthritic changes. Before operation.
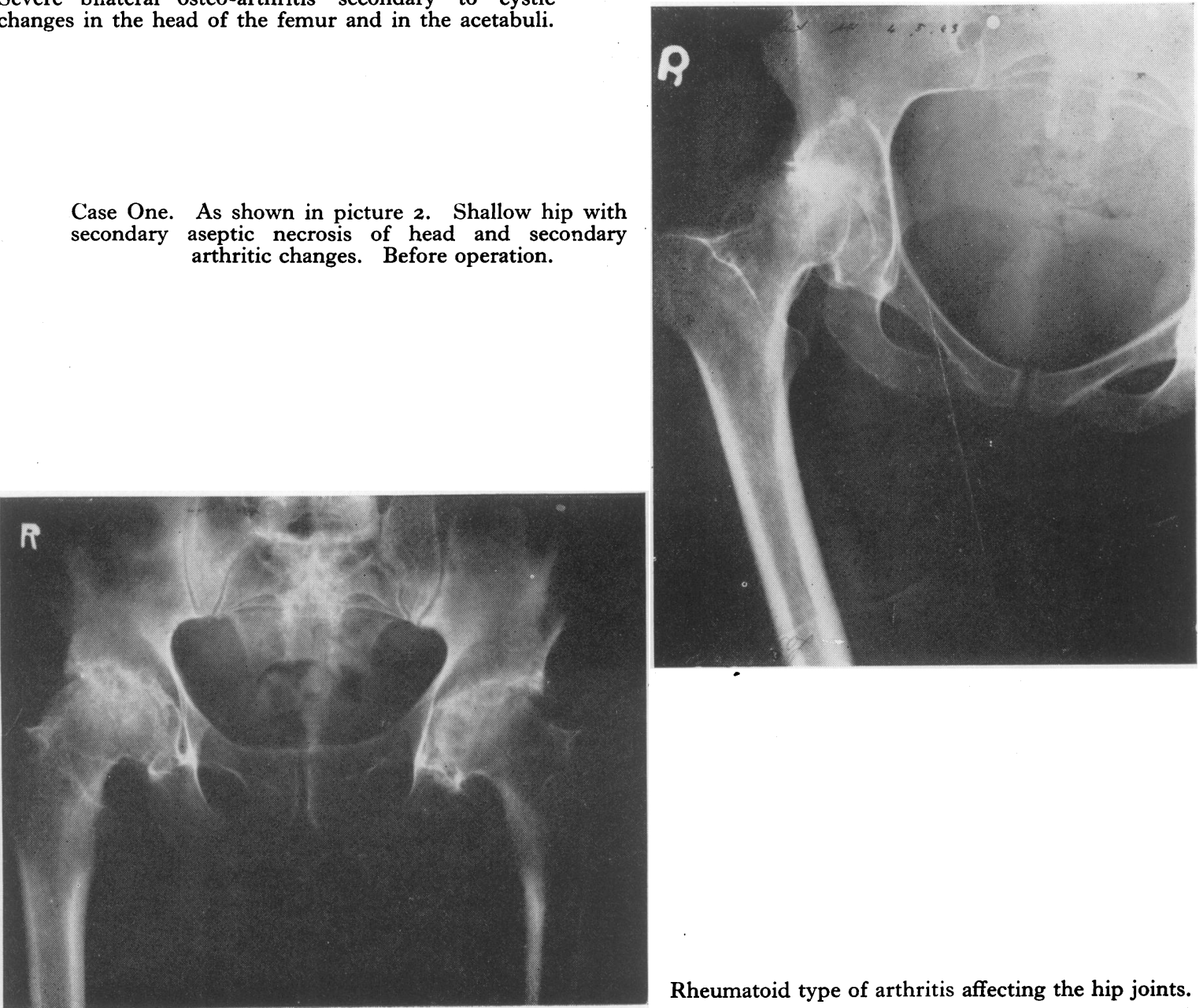

Rheumatoid type of arthritis affecting the hip joints. 


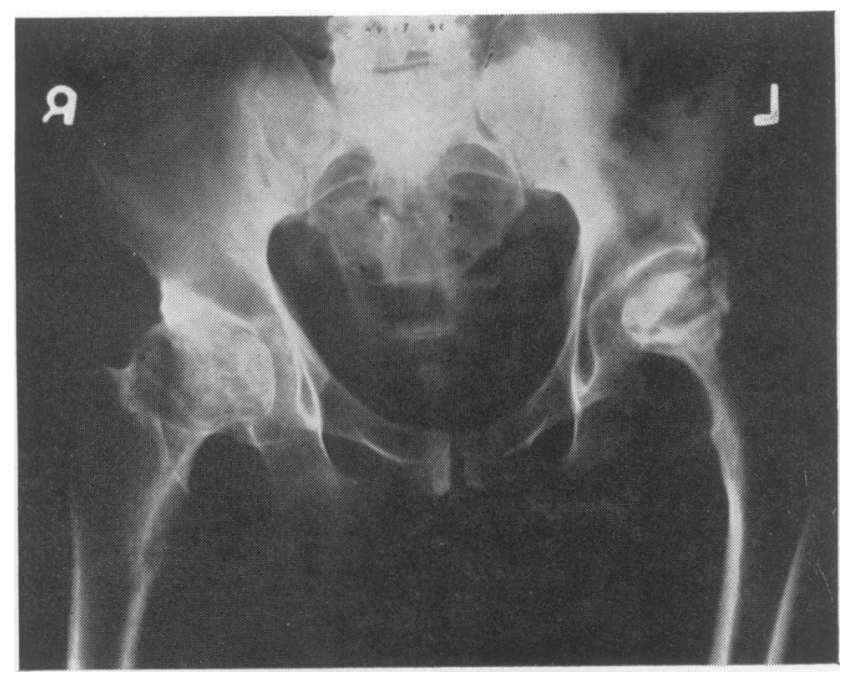

Bilateral aseptic necrosis and secondary arthritis due to Caisson disease.

After cup arthroplasty.

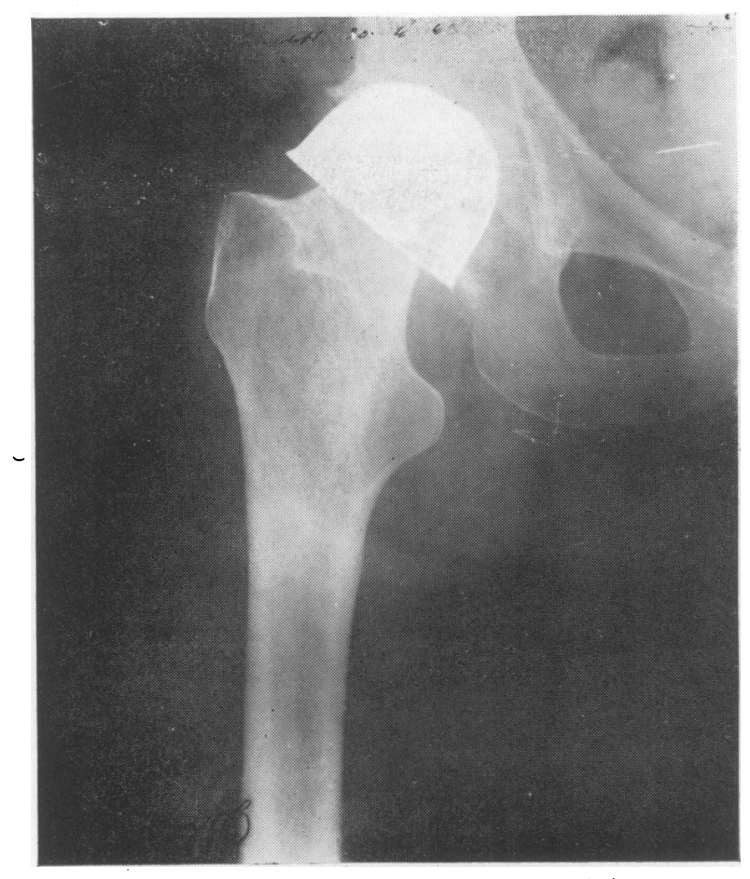




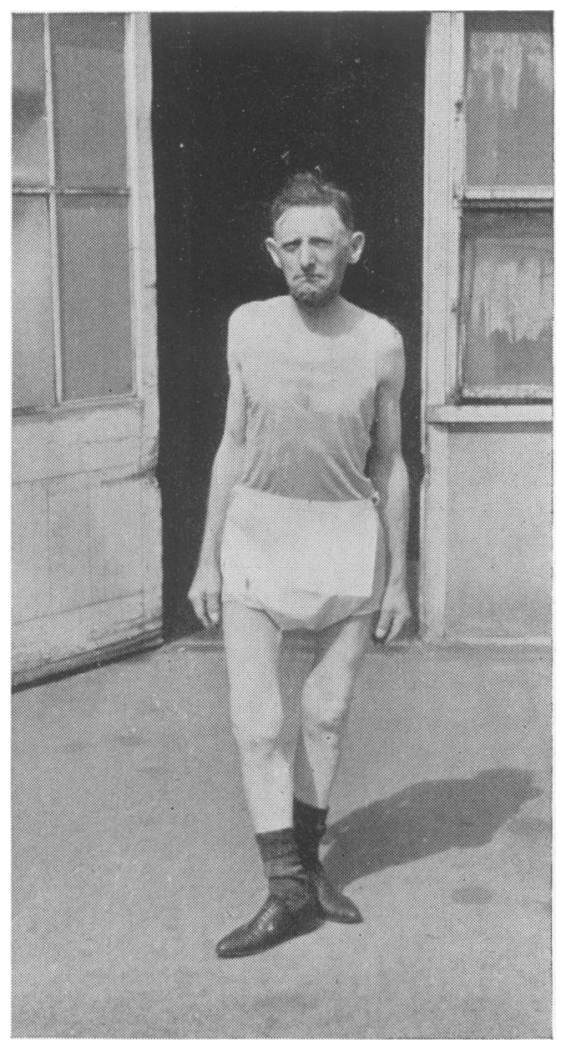

Bilateral osteo-arthritis with scissor leg gait. A suitable case for double cup arthroplasty.

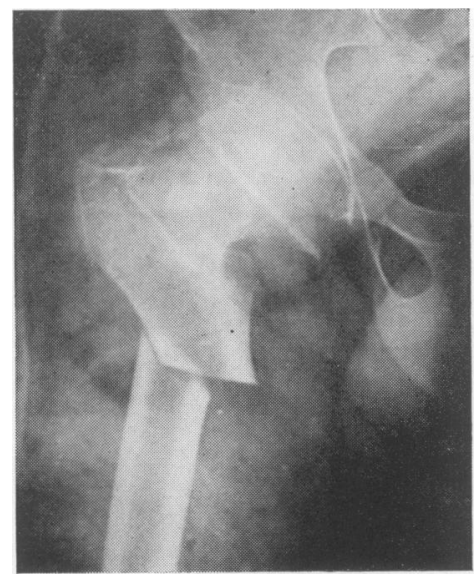

Subtrochanteric osteotomy for unilateral arthritis to correct flexion and adduction. The hip is fixed and therefore painless. Disability is due to adduction.

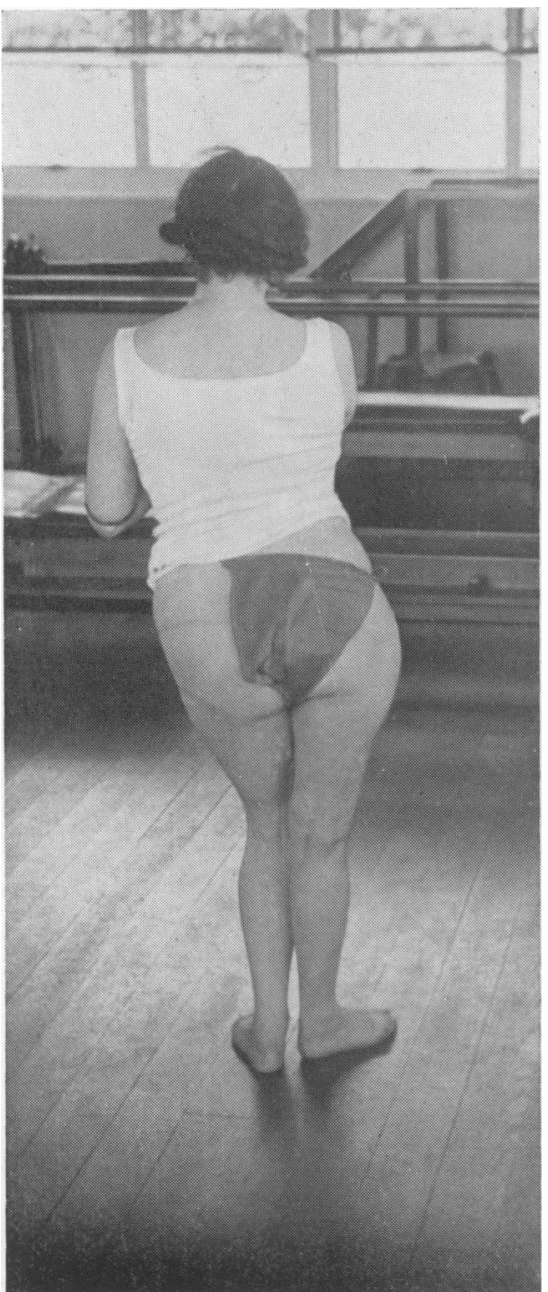

Unilateral osteo-arthritis of right hip showing marked adduction and apparent shortening. This shows Case One at the end of the article.

C1 


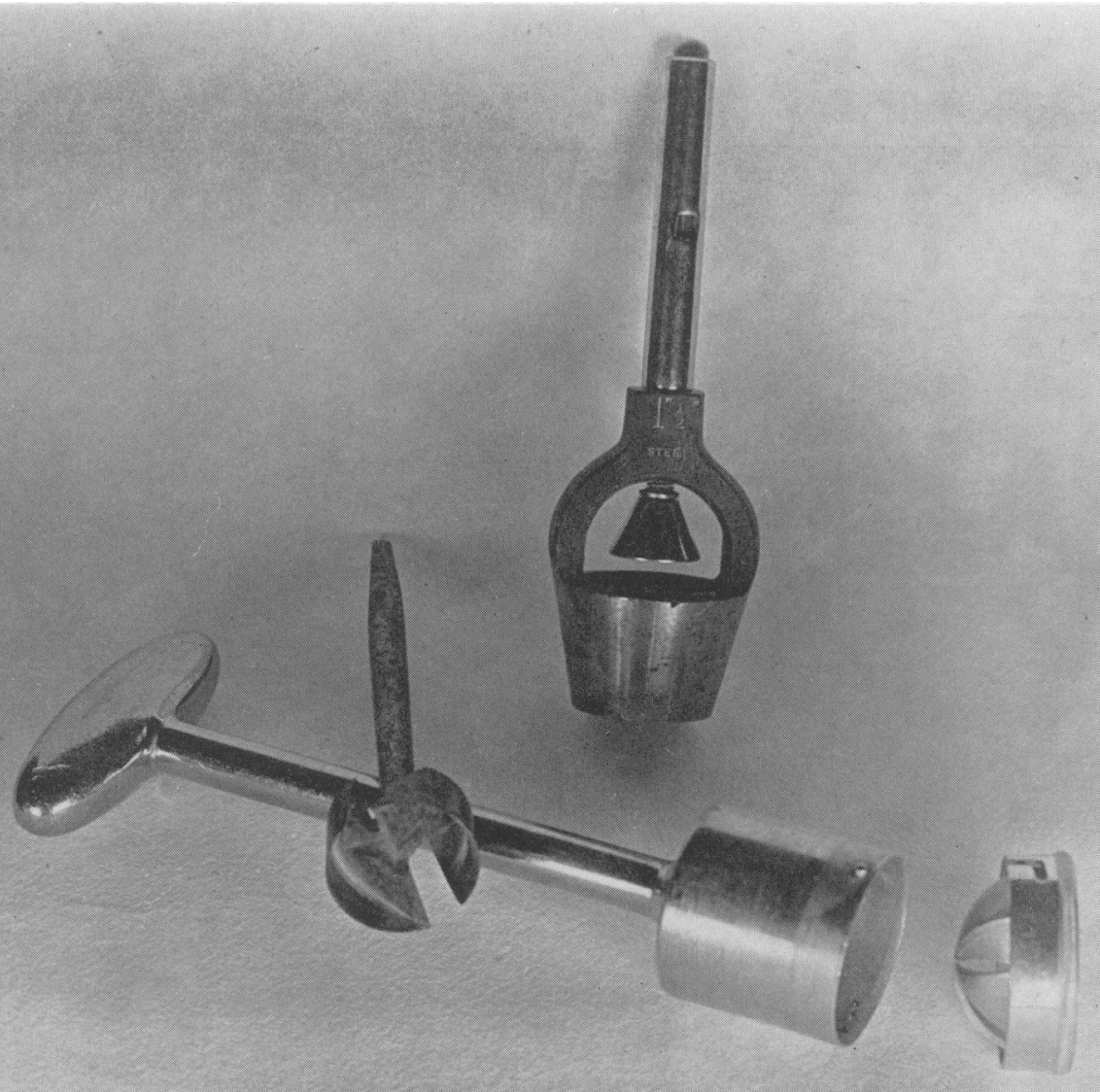

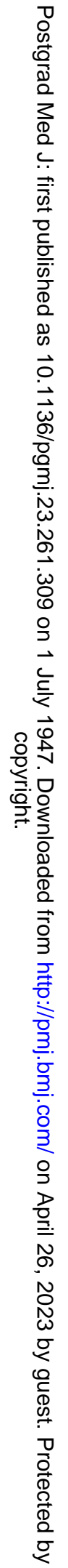

The incision for lateral approach to the hip. 


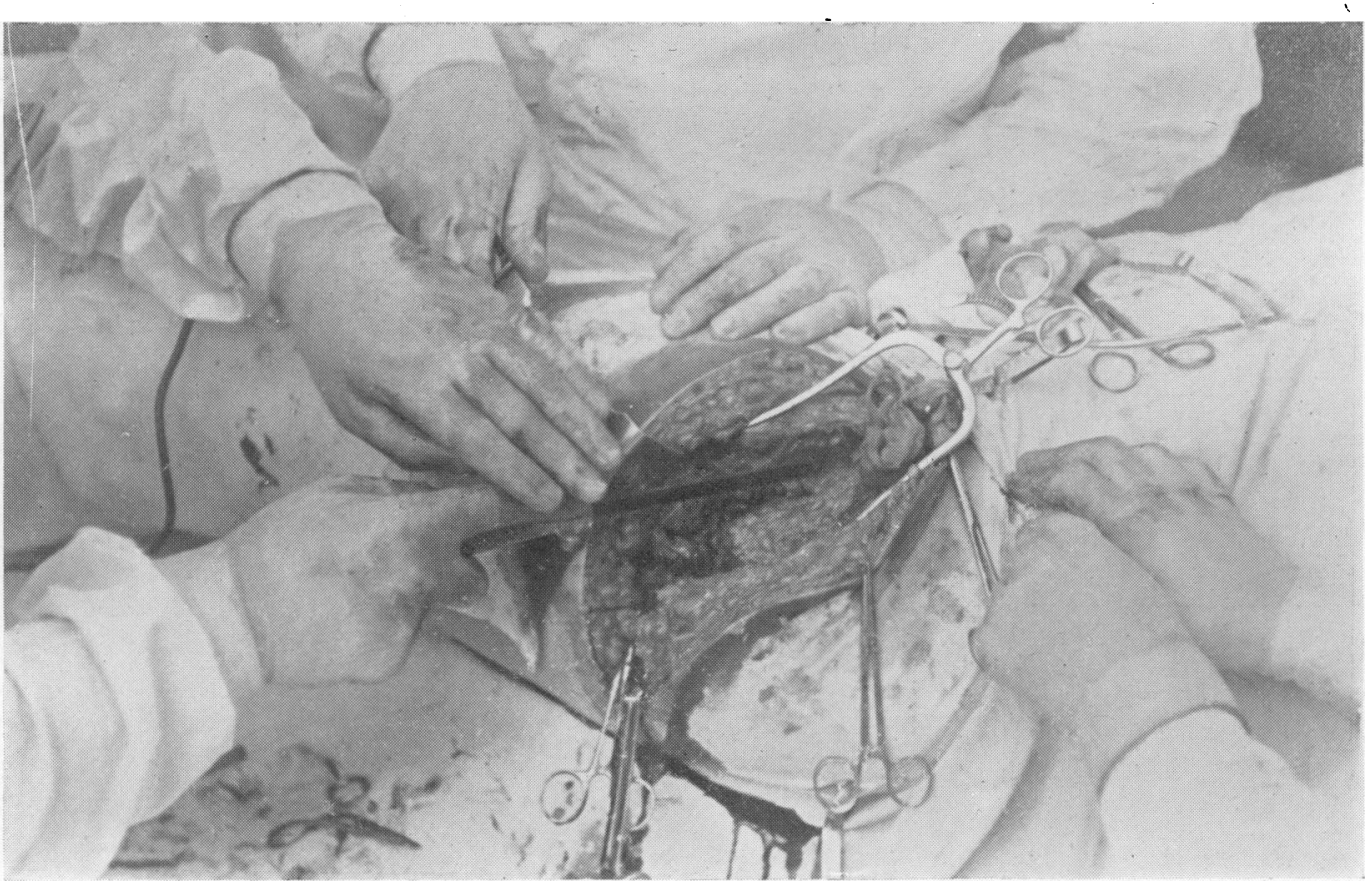

After exposure removing front of the capsule Jwith ycutting? diathermy. I

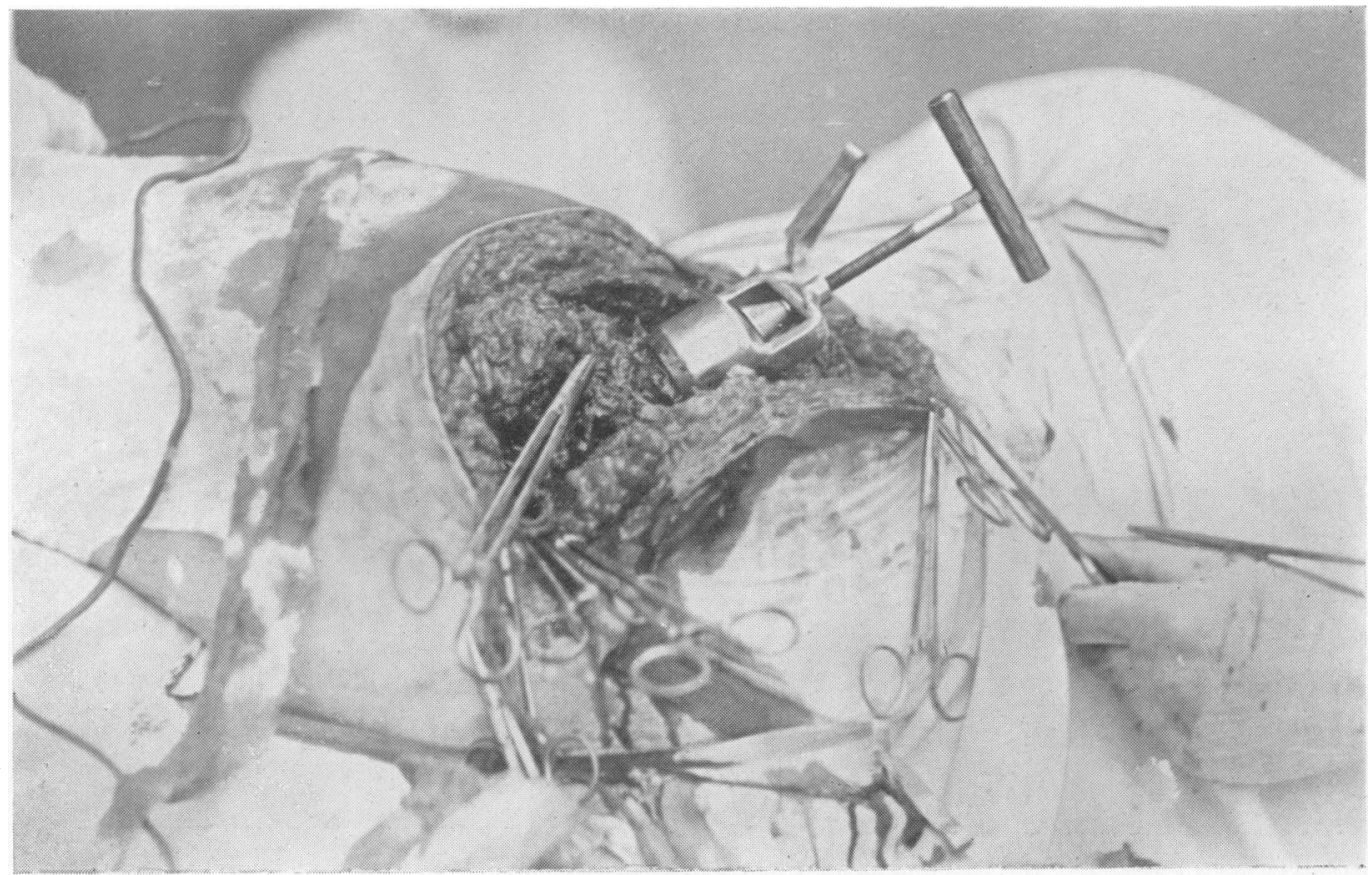

Cutting the head and neck of femur to shape using the author's punch. 


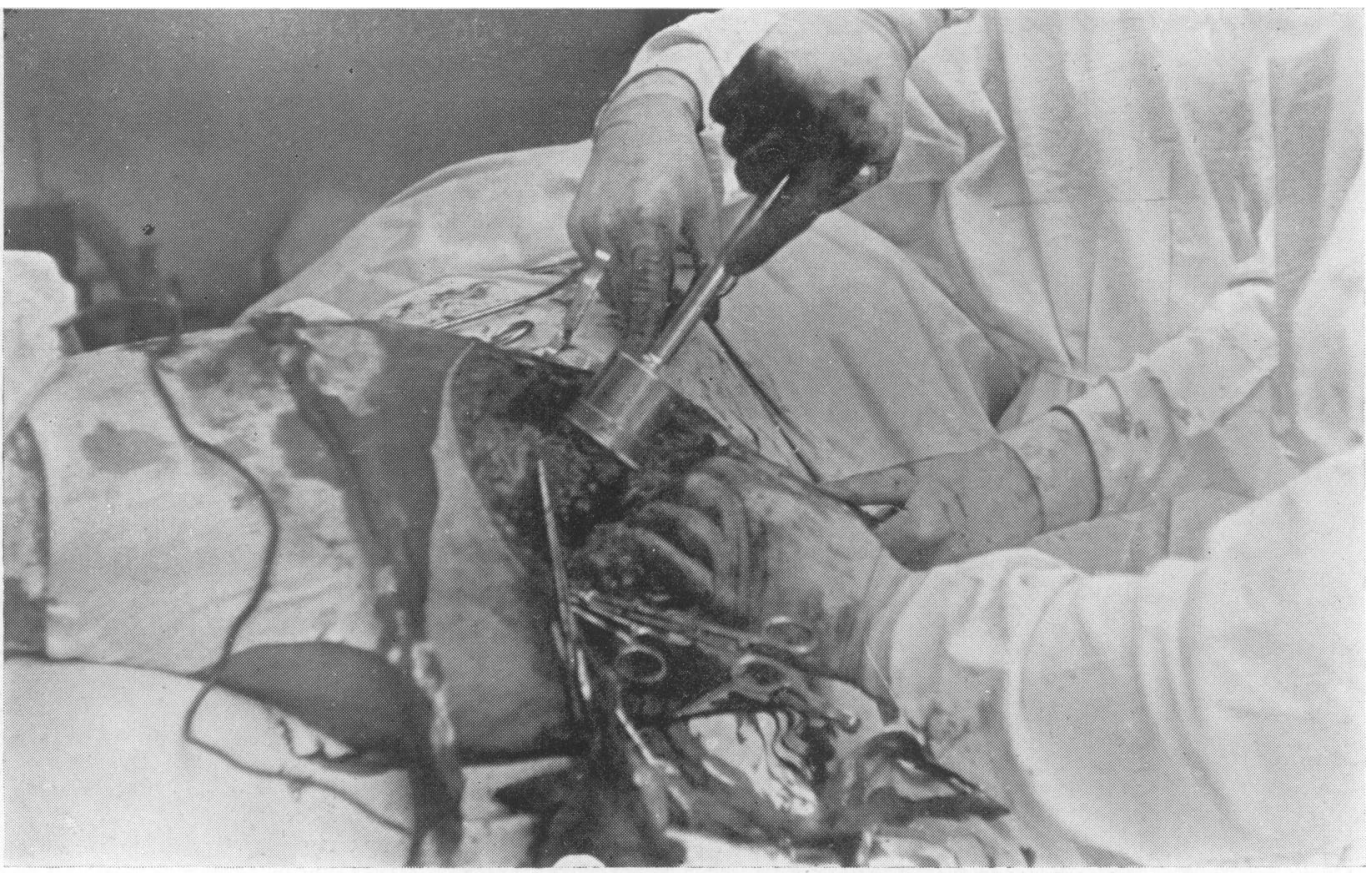

The Pridie femoral head cutter.

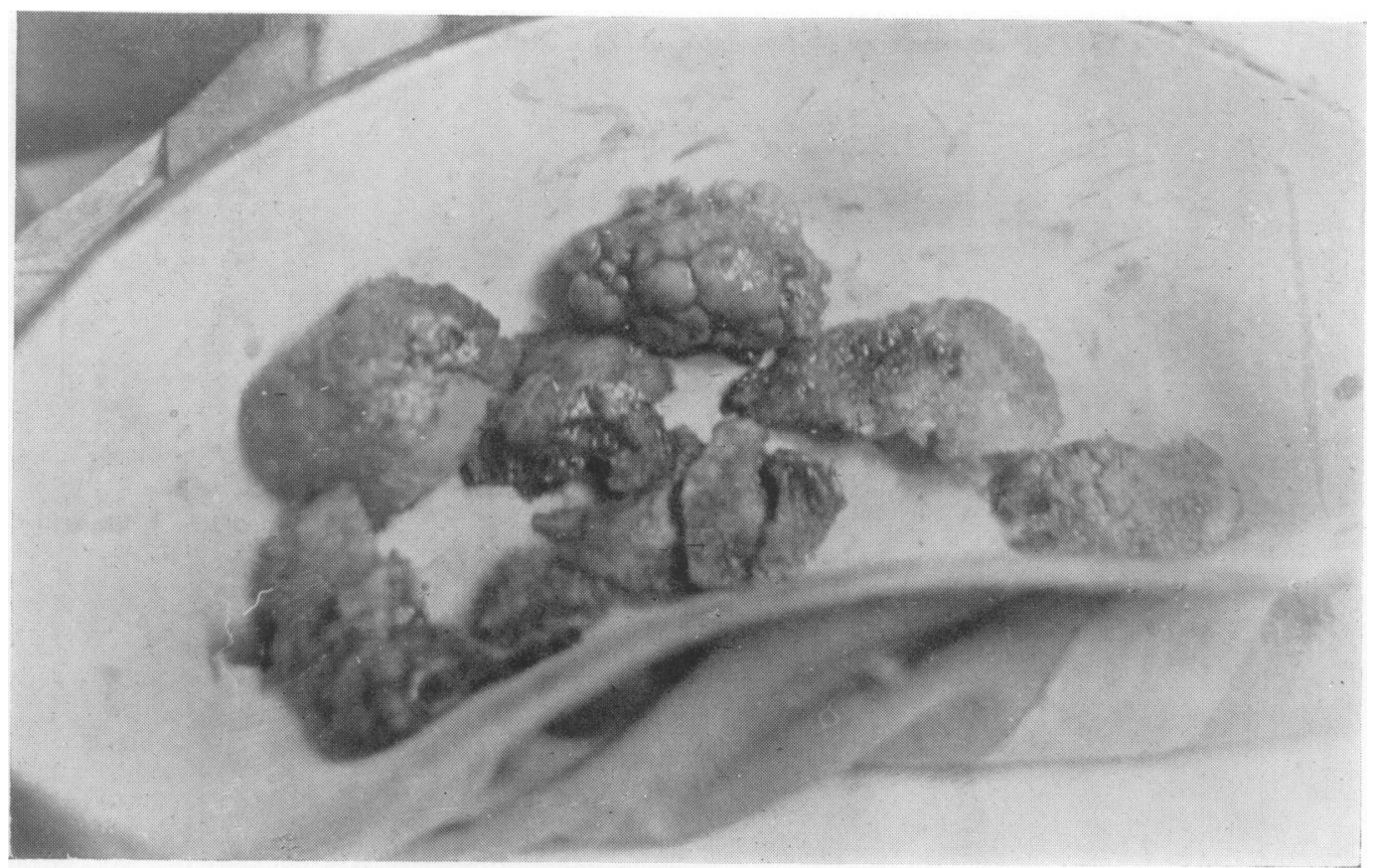

Pieces of femoral head removed by punch. 


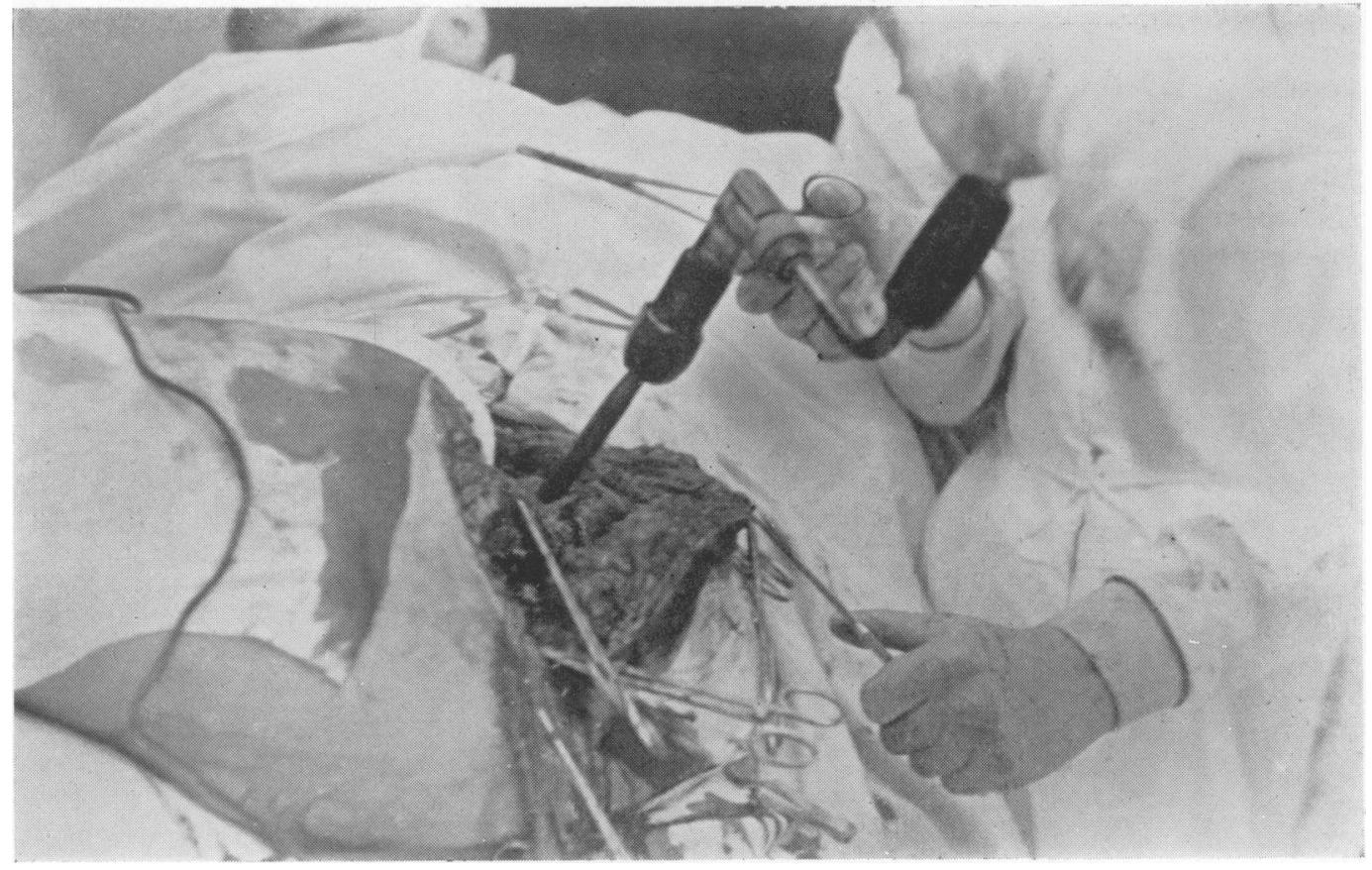

Cutting new acetabulum with Forcner auger-bit.

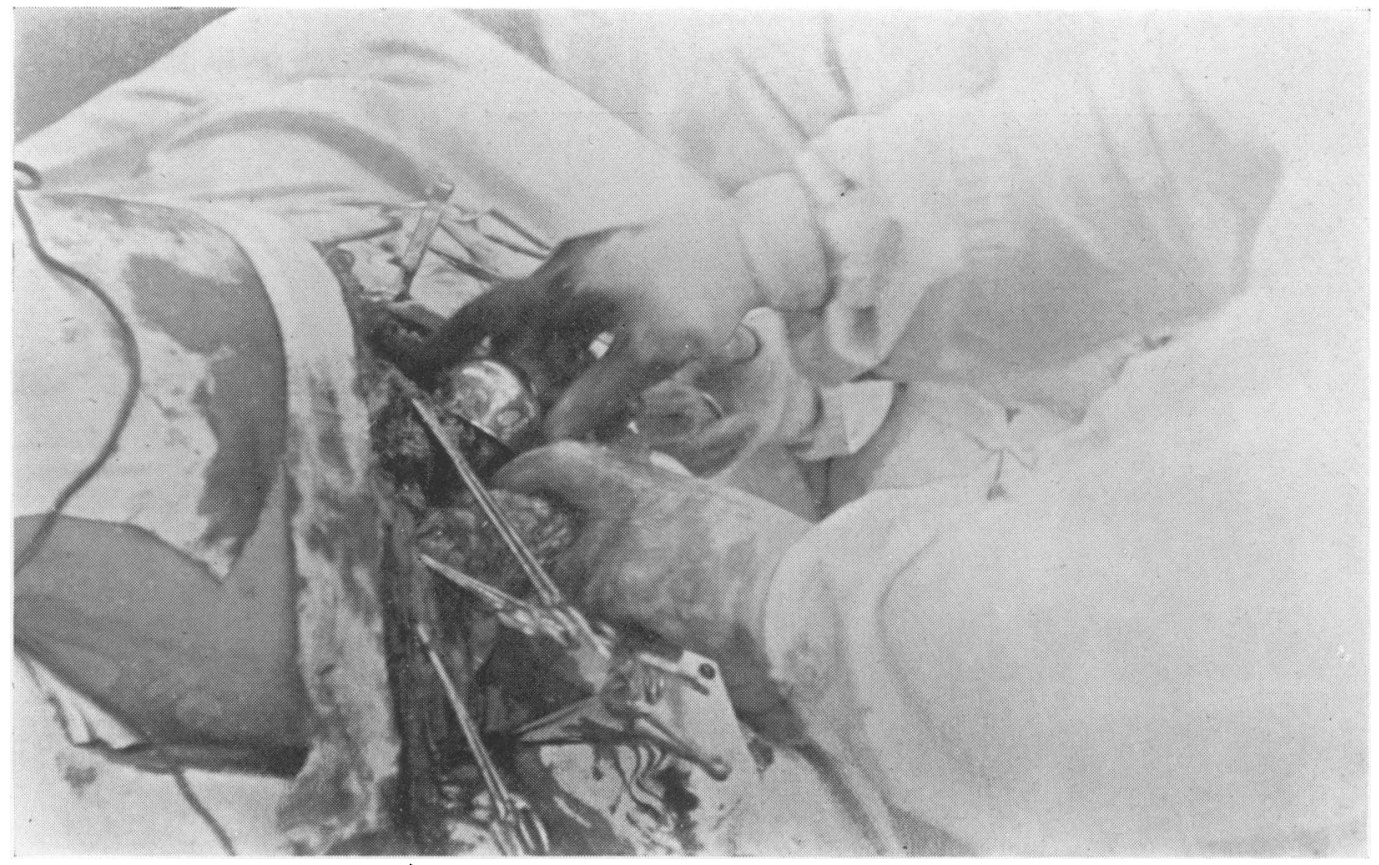

Placing cup on prepared head of femur. 


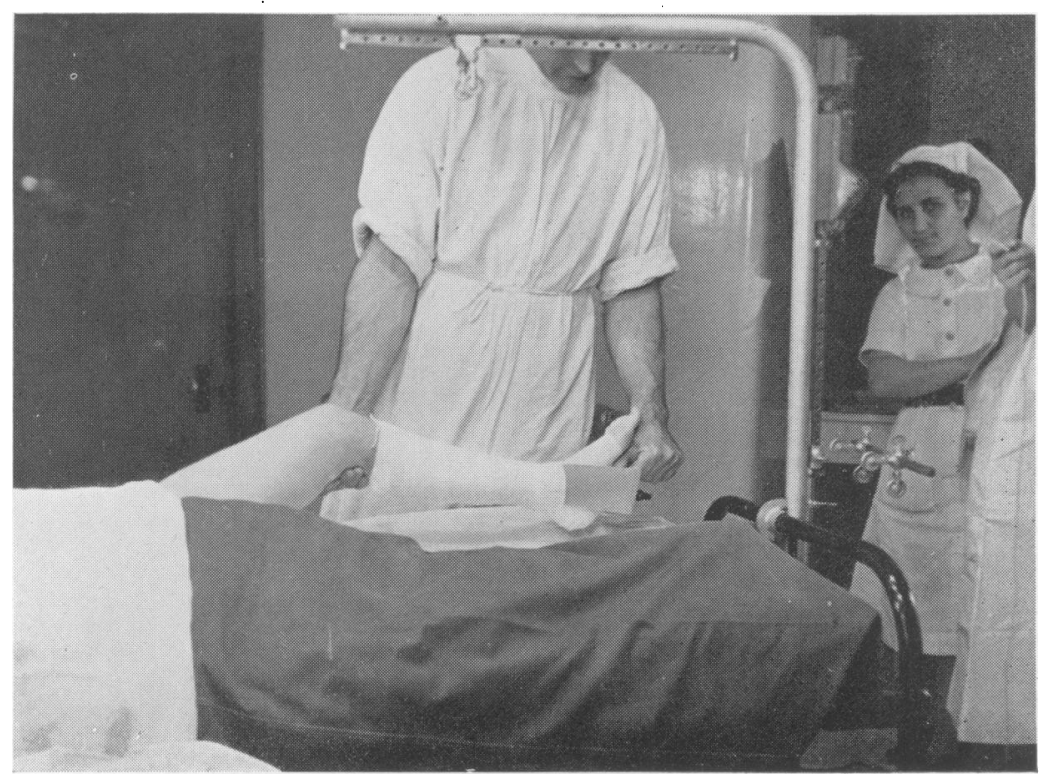

Application of Russell traction using Pridie beam.

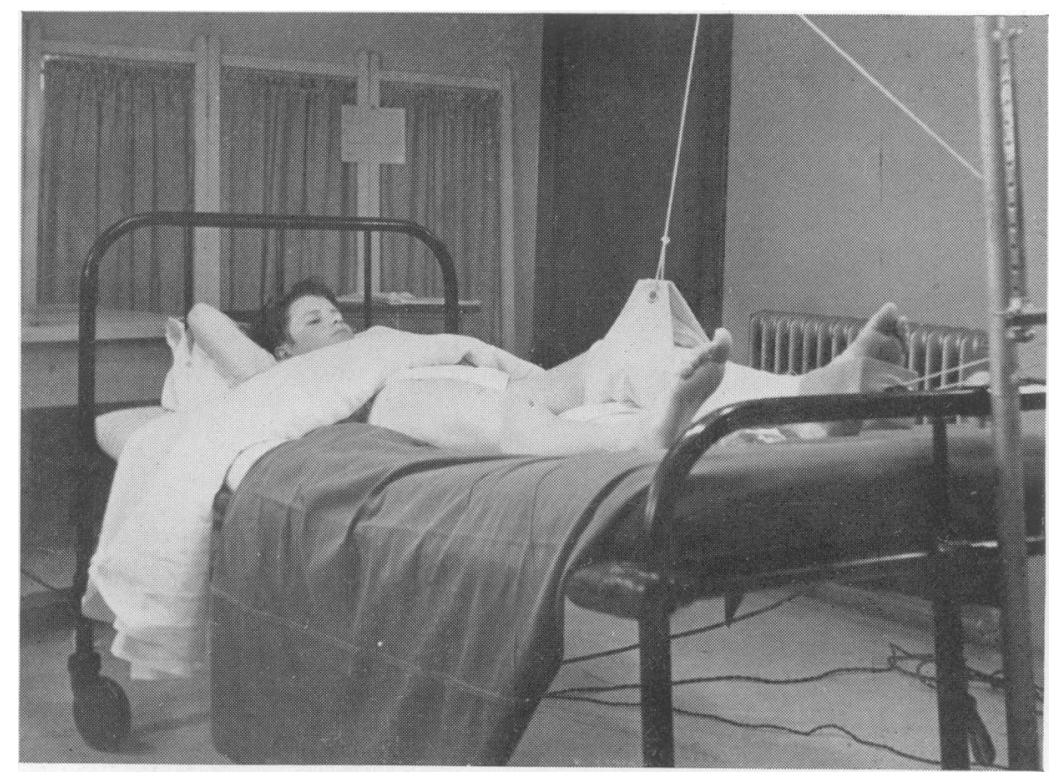

Post-operative suspension of limb by Russell traction. 


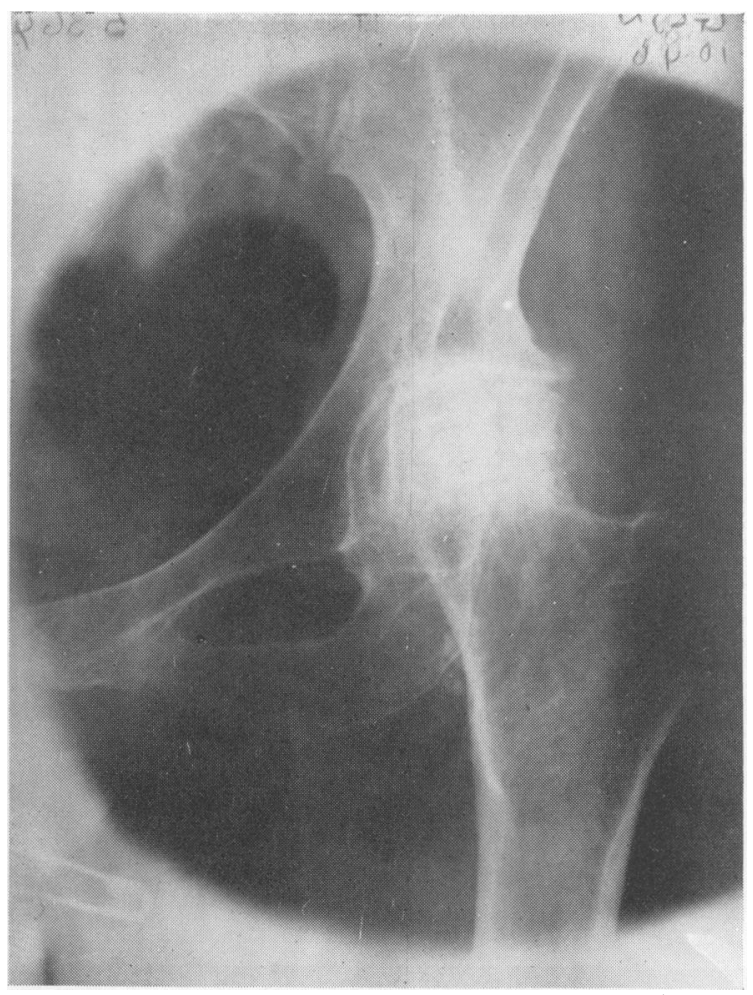

Aseptic necrosis in patient agqd 70 following impacted intracapsular fracture.

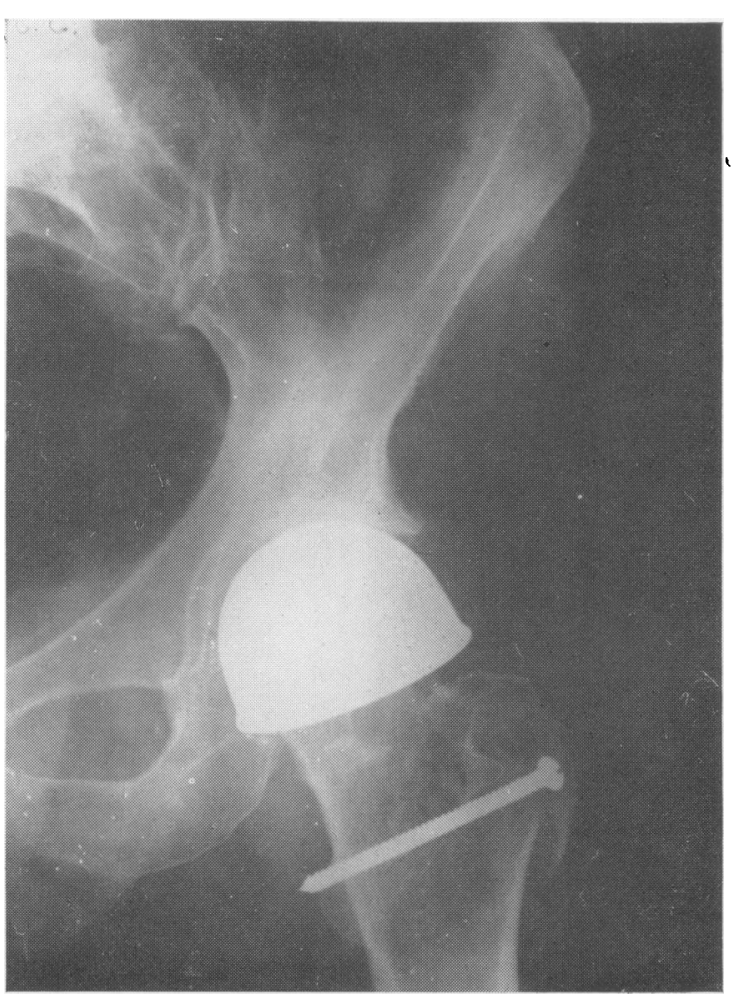

Same case following cup arthroplasty. 


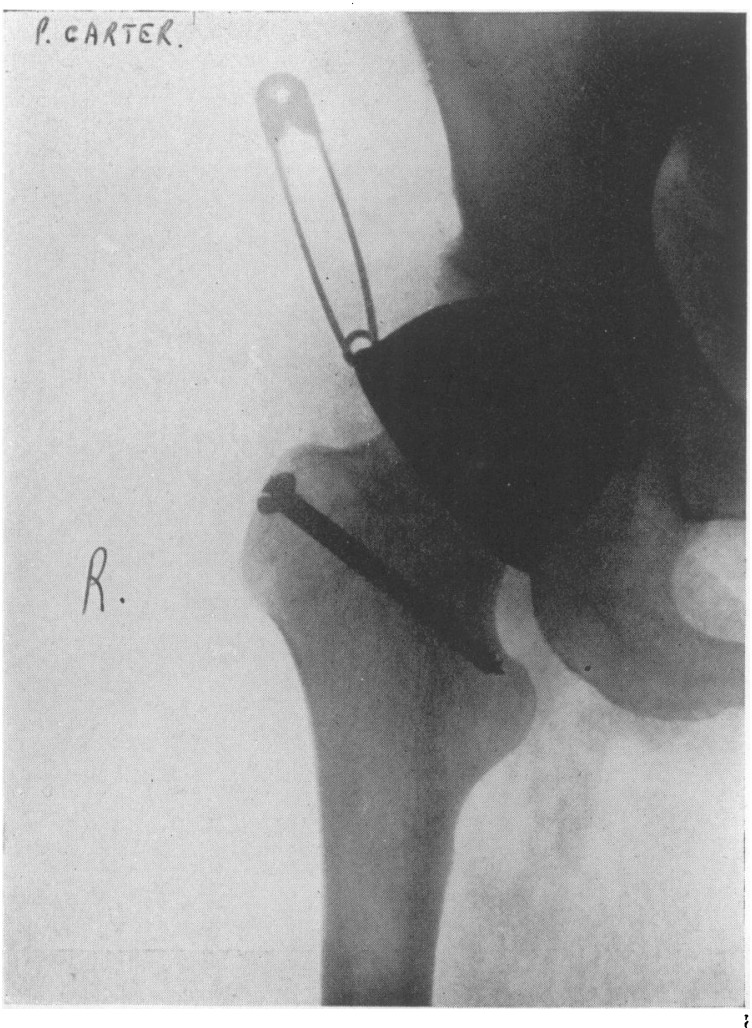

Right and left hips of same case after cup arthroplasty.

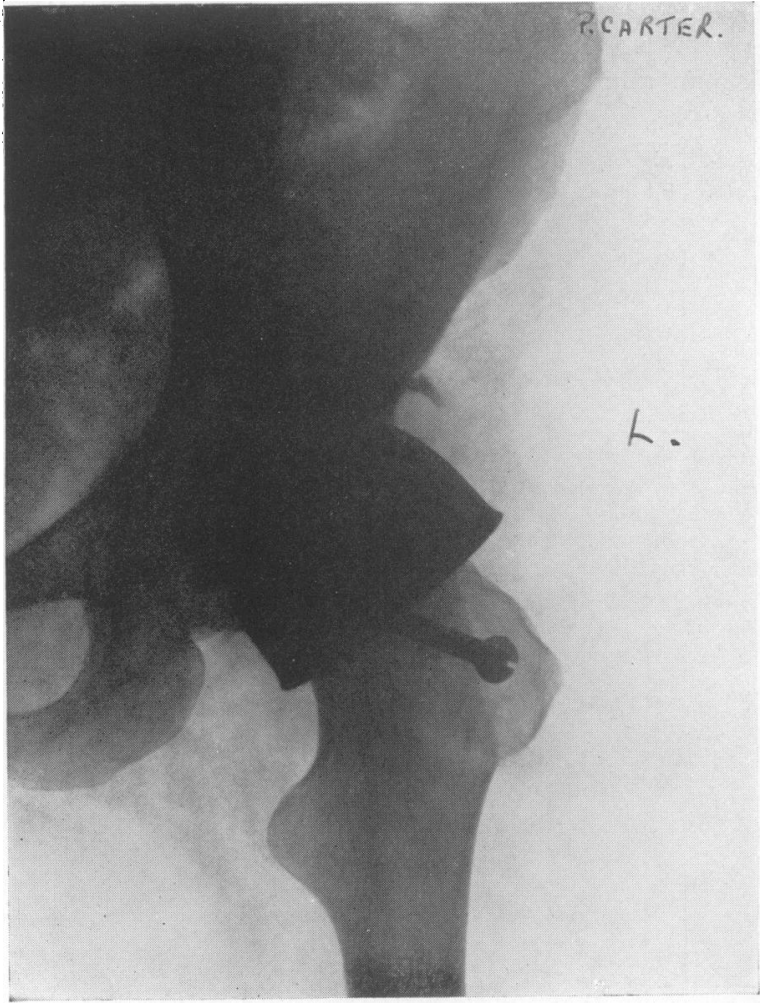




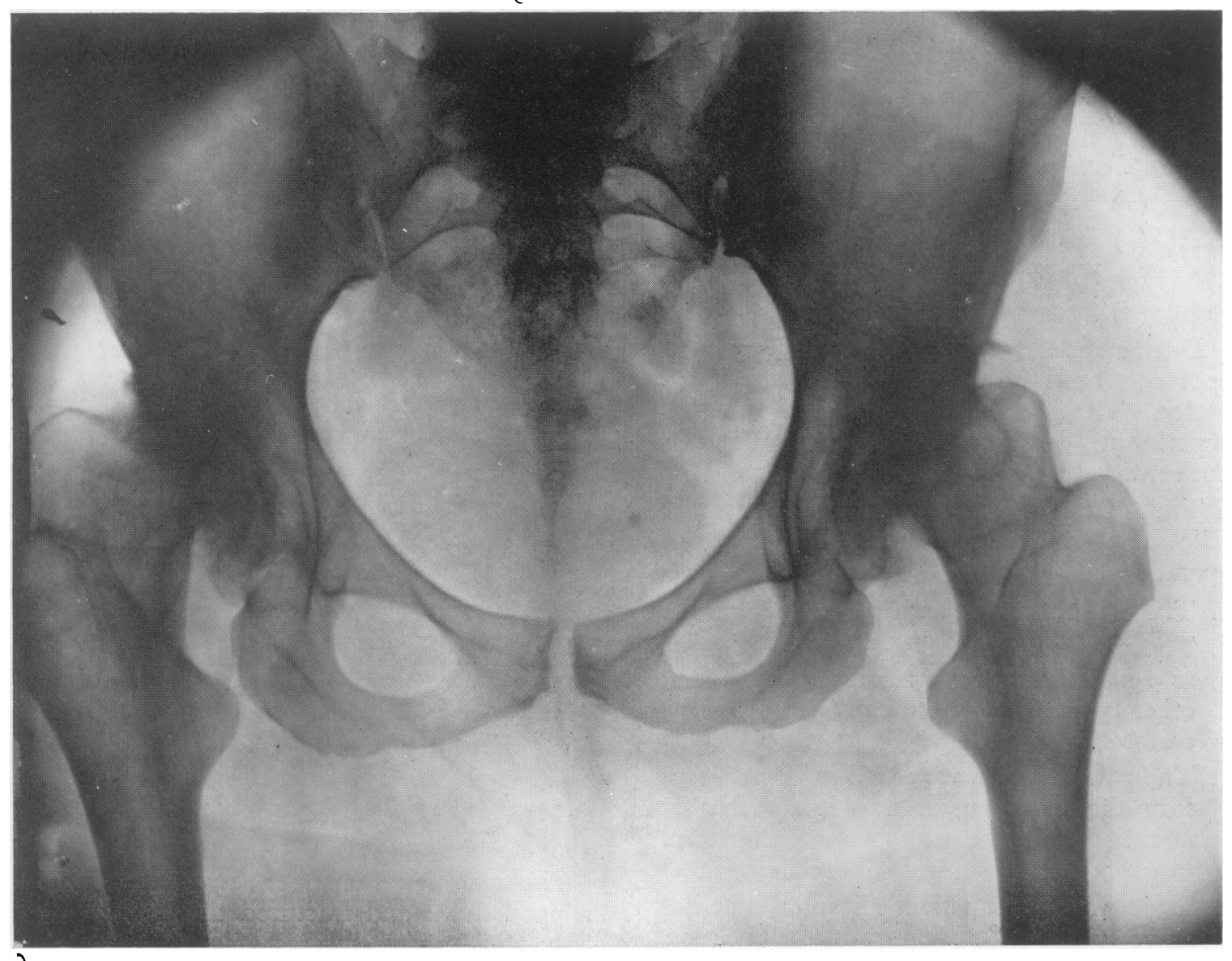

Bilateral congenital hip dysplasia leading to secondary arthritic changes at the age of 26 (Mrs. C.), with pain, cross leg gait and external rotation.

I. Almost all the cases were relieved of pain.

2. Movement varies from nothing in the worst cases to a quarter normal range in 50 per cent. of cases and a half normal range of movement in 25 per cent.

3. The result in the first year is disappointing but improves in the second and third years.

4. The operation is indicated in the following types :

(a) Where the pain is very severe.

(b) Bilateral arthritis.

(c) Stiff painful hip and arthritic spine. (d) Late cases of shallow acetabulum that develop arthritis. These are very difficult cases to arthrodese.

\section{Contraindications :}

(a) Spondylitis ankylo-poietica. T he cup ulcerates through into the acetabulum, becomes surrounded by dense fibrous tissue, and no movement occurs.

(b) Any condition where there is decalcification of the bone. The cup will settle down on the base of the 
neck of the femur, which will absorb, and movement will be restricted by the greater trochanter impinging on the edge of the acetabulum.

\section{Complications :}

(a) Sepsis.

(b) Dislocation of the cup (one case).

(c) Haematoma.

(d) Extra cup arthrodesis.

During the last year I have used the lateral approach and the results have been much better. The immediate result is comparably superior and I see no reason why they should not continue to be good.

The operation in its present form has the following advantages over all other types of operations.

I. The final end result approaches the normal.

2. The patient is in bed for five weeks only, as against 12 weeks minimum with any other type of operation, e.g., arthrodesis or oestotomy.

3. The patient walks very well in eight weeks from the operation, whereas it is nearly six months before the other types of operation can approach this degree of excellence.

4. The saving in the patient's hospital expenses alone, and time off from work or business, make this operation the most satisfactory in this age of shortages of labour and hospital beds.

\section{A typical case}

\section{Mrs. L. Age 50. First seen in 1943.}

History. Four years ago the patient began to limp. The right hip was not painful at that time but three years ago the limp became much worse and she had considerable pain even when resting. She states that she cannot walk at all now because the leg is much shorter and is very stiff and painful.

On examination (Picture No. 2). There is a $60^{\circ}$ fixed flexion of the right hip and it is markedly adducted. There is no real shortenning but $2 \frac{1}{2}$ in. apparent shortening.

$X$-ray findings. A shallow hip joint, a congenital hip dysplasia. The upper quadrant of the head of the femur had collapsed follow- ing a vascular calamity in the head of the femur leading to a local avascular necrosis. The head has wandered upwards and outwards and there is a break in Shenton's line. There is marked adduction and flexion.

May 5, I943. Vitallium cup arthroplasty performed. Anterior Smith Petersen approach used. The synovial membrane was found to be swollen and polypoid with necrotic fragments which had become nipped and detached.

\section{End Result}

May 13, 1946. The patient has completely lost her pain since the operation. She walks with one stick, sits well and states that she can walk two miles for exercise. She can also dress herself and put her own shoes on. On examination there is a slight hip limp with $\frac{1}{2}$ in. shortening of the right leg. There is active flexion to $90^{\circ}$ and a 20 -in. swing at the ankle from extreme adduction to full abduction. She can balance on the right leg without the aid of a stick.

\section{Case two}

Mrs. G. Age 72. First seen August 20, 1946.

History. In December, 1935, the patient slipped down and fractured the right femur. She was treated by rest for three months after which the fracture united. After walking she began to develop arthritic changes in the right hip and X-ray showed a condition of aseptic necrosis of the head which was starting to break up.

August, 1946. The patient complained of severe pain in the right hip both at night and during the day. The pain was so severe and crippling that an active life was becoming impossible.

On examination. There was limitation of all movements of the right hip with loss of rotation, abduction and $25^{\circ}$ fixed flexion.

October 2, 1946. Cup arthroplasty performed. Lateral approach used. Time of operation was just under one hour and patient did not need a transfusion. She made an uninterrupted recovery and has now completely lost all pain.

\footnotetext{
* Almost all the cup arthroplasties performed during the past four years have used stainless steel caps made by Down Brothers, London. I can see no advantage in Vitallian over stainless steel.
} 